\title{
Daily rhythms of pituitary-ovarian function in the immature hamster are independent of adrenal and pineal influence
}

\author{
R. S. Donham, M. D. Rollag* and M. H. Stetson \\ Physiology Program, School of Life and Health Sciences, University of Delaware, Newark, \\ Delaware 19716, U.S.A.; and *Department of Anatomy, Uniformed Service University for Health \\ Sciences, Bethesda, Maryland 20814, U.S.A.
}

\begin{abstract}
Summary. In female hamsters, the daily rhythm of LH appeared on the 15 th or 16 th day after birth with a peak occurring at about 16:00 h (14L:10D, lights on 06:00 h). Progesterone concentrations increased and became rhythmic a few days later. In serum samples collected at 14,16,18,20,25,30,40 and 60-62 days of age between 13:00 and 23:00 h, significant rhythms of serum cortisol and corticosterone concentrations were not detected before 25 days of age; furthermore, the phase of the rhythms did not stabilize to the adult pattern until about 40 days of age. As in the adult, significant rhythms were present in both sexes and the levels of cortisol were greater than those of corticosterone. Injection of pig ACTH (50 i.u./kg body wt, i.p.) significantly increased serum cortisol by 10 days of age, but corticosterone did not respond until 25 days of age. Thus, for cortisol at least, the appearance of 24-h rhythms in the serum is probably not dependent on the ability of the adrenal to respond to ACTH. Ovariectomy had no effect on the late afternoon surge of serum cortisol; similarly, adrenalectomy of immature females did not abolish the surge of LH. Ovariectomy did not alter the daily rhythm of pineal melatonin content and pinealectomy had no effect on the daily afternoon surge of LH. These results demonstrate functional independence of circadian rhythms in the pituitary-gonadal axis and the pituitary-adrenal axis of the immature hamster and also independence of daily rhythms of pineal melatonin and pituitary release of $\mathrm{LH}$.
\end{abstract}

Keywords: hamsters; rhythms; gonadotrophins; glucocorticoids; pineal

\section{Introduction}

The oestrous cycle of the Syrian hamster is an invariate $96 \mathrm{~h}$ in length, but is dependent on an intact circadian oscillator system localized to the suprachiasmatic nuclei (SCN) (Stetson \& WatsonWhitmyre, 1976; Stetson \& Anderson, 1980). The circadian oscillator system and the associated neuroendocrine effector system matures before puberty; daily rhythms of LH and FSH begin at about 16 days of age (Smith \& Stetson, 1980; Donham et al., 1984) whereas first ovulation occurs between 30 and 40 days of age.

Circadian rhythms also characterize the activity of the adrenal cortex and the pineal gland and are also derived from activity of the SCN (Moore \& Eichler, 1972; Rusak \& Zucker, 1979; MooreEde, 1986). So far as we are aware, the ontogeny of rhythmic adrenal function has not been described for the hamster, but in the rat the circadian rhythm of circulating corticosterone develops between 20 and 30 days of age (Allen \& Kendall, 1967; Takahashi et al., 1979). The pineal is of particular interest because it is crucial to interpretation of environmental photoperiod in several seasonally breeding species (Goldman \& Darrow, 1983; Stetson \& Watson-Whitmyre, 1984) and 
regulates the timing of puberty in sheep (Foster et al., 1985), the Djungarian hamster (Goldman et al., 1984) and perhaps the rat (Sizonenko et al., 1985). The influence of the pineal appears to be expressed through the daily rhythm of melatonin. In the hamster the rhythm of pineal melatonin is first detectable at about 15 days of age (Tamarkin et al., 1980; Rollag \& Stetson, 1981), i.e. it coincides with that of the beginning of rhythmic function of pituitary-gonadal axis.

In the present studies the development of rhythmic function of the pituitary-adrenal axis was compared with that of the pituitary-ovarian axis. Extirpation of the ovaries, the adrenals, and the pineal was also used to determine the effect on rhythmic function of the other systems.

\section{Materials and Methods}

The Syrian hamsters (Mesocricetus auratus) used in these investigations were produced in the colony at the University of Delaware. The animals were maintained in a photoperiod of $14 \mathrm{~h} \mathrm{light} / 10 \mathrm{~h}$ darkness (lights on at 06:00 h) and provided with food and water ad libitum. Young animals were weaned at 20 or 21 days of age, sorted according to sex and held 7-10 per cage. Adult females were individually housed; males were held 5-7 per cage.

Experiments. To assess the potential confounding effects of handling stress on serum cortisol concentrations, a preliminary study was conducted in which trunk blood was collected at timed intervals after disturbance typical of that preliminary to the normal collection of samples (including cage movement and handling of animals). No increase in serum cortisol values was found after disturbance for up to at least $7 \mathrm{~min}$. These results agree with a report that, whereas 15 to $30 \mathrm{~min}$ of exposure to a novel environment progressively increased serum cortisol concentrations in hamsters, exposure for 5 min was insufficient to do so (Weinberg \& Wong, 1986).

Blood samples $(1 \mathrm{ml})$ were collected at $1-\mathrm{h}$ intervals throughout the day from dioestrous females that were 4-10 months old. Each female was bled twice by cardiac puncture, at 4-day intervals. Serum hormone values from these samples were used to determine the ideal sampling times in subsequent studies with adult and immature animals. Thereafter, trunk blood was collected over a more restricted portion of the day (during that portion in which concentrations of glucocorticoids increase and reach maximal values) to conserve animals. Blood was collected between 13:00 and 23:00 h from 14-, 16-, 18-, 20-, 25-, 30-, 40- and 60-day-old males and females and serum cortisol and corticosterone concentrations were measured by radioimmunoassay (RIA). To compare the age of onset of daily rhythms of cortisol and corticosterone with that of ability of the adrenal cortex to respond to ACTH, pig adrenocorticotrophin (ACTH; Sigma Chemical Co., St Louis, MO) was injected once (i.p., $50 \mu \mathrm{g} / \mathrm{kg}$ body wt, in $0.9 \%$ (w/v) $\mathrm{NaCl})$ at about $13: 00 \mathrm{~h}$ and blood was collected $30 \mathrm{~min}$ later.

Surgical adrenalectomy, ovariectomy and pinealectomy were performed using pentobarbitone anaesthesia $(65 \mathrm{mg} / \mathrm{kg}$ body wt). To determine the effect of removal of the ovaries on the glucocorticoid rhythms, both ovaries were removed at 15 days of age and blood samples collected at 13:00, 17:00 and 21:00 h at 30 days of age. To determine the effect of adrenalectomy on the afternoon surge of $\mathrm{LH}$, the adrenals were removed after weaning at 21 days and the animals were killed at appropriate times at 27 days of age. Survival was promoted in the adrenalectomized animals by supplementing drinking water with $1 \%(\mathrm{w} / \mathrm{v}) \mathrm{NaCl}$ and $0.2 \%(\mathrm{w} / \mathrm{v})$ sodium saccharine. To determine the effect of ovariectomy on the pineal melatonin rhythm the ovaries were removed at 21 days of age and the pineal glands collected at 26,28 and 30 days of age at hourly intervals throughout the 24 -h period. Blood from these animals was assayed for serum LH and the concentrations found have been reported (Donham et al., 1985). To determine the effect of pinealectomy on the daily surge of serum $\mathrm{LH}$, pinealectomy was performed at 15 days of age, before the onset of the daily surge of $\mathrm{LH}$, and samples of trunk blood were collected at 13:00 and 17:00 h when the females were 30 days old.

Assays. Cortisol and corticosterone were measured in separate aliquants of each serum sample. Before RIA for cortisol, the serum samples $(20-25 \mu \mathrm{l})$ were diluted $\times 20$ with distilled water and heated for $20 \mathrm{~min}$ at $95^{\circ} \mathrm{C}$ to reduce binding of cortisol to endogenous proteins. Duplicate portions $(100 \mu l)$ were then transferred to assay tubes before addition of equal volumes of $\left[1,2,6,7-{ }^{3} \mathrm{H}\right] \operatorname{cortisol}\left(10^{-2} \mu \mathrm{Ci} /\right.$ tube; NEN Research Products, Boston, MA, U.S.A.) and antiserum (F3-314; Endocrine Research Products, Tarzana, CA, U.S.A.). For assay of corticosterone, $50 \mu 1$ sera were first extracted with methylene chloride. A trace of $\left[1,2,6,7-{ }^{3} \mathrm{H}\right]$ corticosterone $\left(10^{-3} \mu \mathrm{Ci}\right)$ was added to each sample before extraction to determine methodological losses. The extracted sample was dried under $\mathrm{N}_{2}$ and redissolved with phosphate buffer and then samples $(100 \mu \mathrm{l})$ were transferred to duplicate assay tubes and to a scintillation vial. Equal volumes of tritiated corticosterone $\left(10^{-2} \mu \mathrm{Ci}\right.$ ) and antiserum (Endocrine Research Products, B3-163) were added to the assay tubes. For both glucocorticoid assays, the samples were incubated for $24 \mathrm{~h}$ at $4{ }^{\circ} \mathrm{C}$ and then bound and free fractions were separated by dextran-coated charcoal.

The minimum amount of cortisol that was detectable was $30 \mathrm{pg} /$ tube. Regression analysis of results of assays in which cortisol was added to charcoal-stripped hamster serum yielded coefficients of determination $\left(r^{2}\right)$ of 0.99 over the range of 50 to $800 \mathrm{pg} /$ tube of added steroid. Intra-assay coefficient of variation (CV), as determined by repeated measurements of serum pools with high and low levels of endogenous steroids, is $8.6 \%$; interassay CV, based on repeated measurement of the same pools in 11 assays is $14.7 \%$. The antiserum cross-reacts significantly with the natural steroids 21 -desoxycortisol $(7 \cdot 5 \%$ of cortisol at $50 \%$ bound), desoxycortisol $(4 \cdot 7 \%)$, cortisone $(3 \cdot 3 \%)$ tetrahydrocortisol (2.3\%) and corticosterone $0 \cdot 15 \%$ (as reported by the manufacturer). 
The minimum detectable amount of corticosterone was about $20 \mathrm{pg} /$ tube. Comparison of the results of assays in which samples were measured with and without chromatography (Celite column chromatography: method of Abraham et al., 1977) gave an $r^{2}$ value of 0.90 (from 50 to $1500 \mathrm{pg} /$ tube). Addition of corticosterone to charcoalstripped serum yielded good accuracy $(5 \mathrm{ng} / \mathrm{ml}$ measured $5.8 \pm 0.30 \mathrm{ng} / \mathrm{ml} ; 10 \mathrm{ng} / \mathrm{ml}, 10.1 \pm 1.8 \mathrm{ng} / \mathrm{ml} ; 20 \mathrm{ng} / \mathrm{ml}$, $19.9 \pm 2.0 \mathrm{ng} / \mathrm{ml}$ ). Intra-assay $\mathrm{CV}$ was $9.0 \%$ for repeated measurement of high and low level pools; inter-assay $\mathrm{CV}$ was $17.8 \%$. The antiserum is highly specific; of 25 natural and synthetic steroids, maximum cross-reaction is with desoxycorticosterone (4\%) (information provided by Endocrine Sciences). Cortisol cross-reacts $0.4 \%$ (verified in our laboratory).

LH and progesterone were measured as described by Donham et al. (1984). The sensitivity of the LH RIA is about $1.5 \mathrm{ng} \mathrm{rLH}-\mathrm{RP}-2 / \mathrm{ml}$ and the inter-assay CV is $13.2 \%$. The sensitivity of the progesterone assay is about $1.0 \mathrm{ng} / \mathrm{ml}$ serum with an inter-assay $\mathrm{CV}$ of $12.2 \%$. For both $\mathrm{LH}$ and progesterone assays, intra-assay variance is less than interassay CV. Pineal melatonin content was measured as described by Stetson et al. (1986). Sensitivity of this assay is $5 \mathrm{pg} /$ pineal $(=0.5 \mathrm{pg} /$ tube $)$ and the inter- and intra-assay variances are $<15 \%$.

Statistics. Statistical comparisons were made by non-parametric analyses (Wilcoxon-Mann-Whitney two-sample test and Kruskal-Wallis $k$ sample test).

\section{Results}

As in previous experiments, by 16 days of age there was a significant $(P<0.01)$ afternoon surge in the concentrations of $\mathrm{LH}$, which persisted and was even accentuated at 18-25 days of age (Fig. 1). A late afternoon surge of progesterone was measurable by 18 days of age $(P<0.01)$ and this gradually increased through Day 25 . In contrast, the appearance of the daily surges of adrenal glucocorticoids did not occur until 25-30 days of age (Fig. 2). The concentrations of both hormones were uniformly low, frequently below the assay sensitivities, in samples collected at 16 and 18 days of age and are therefore not reported. The timing of the daily surges of $\mathrm{LH}$ and progesterone was relatively consistent as compared with those of cortisol and corticosterone; the peak of the

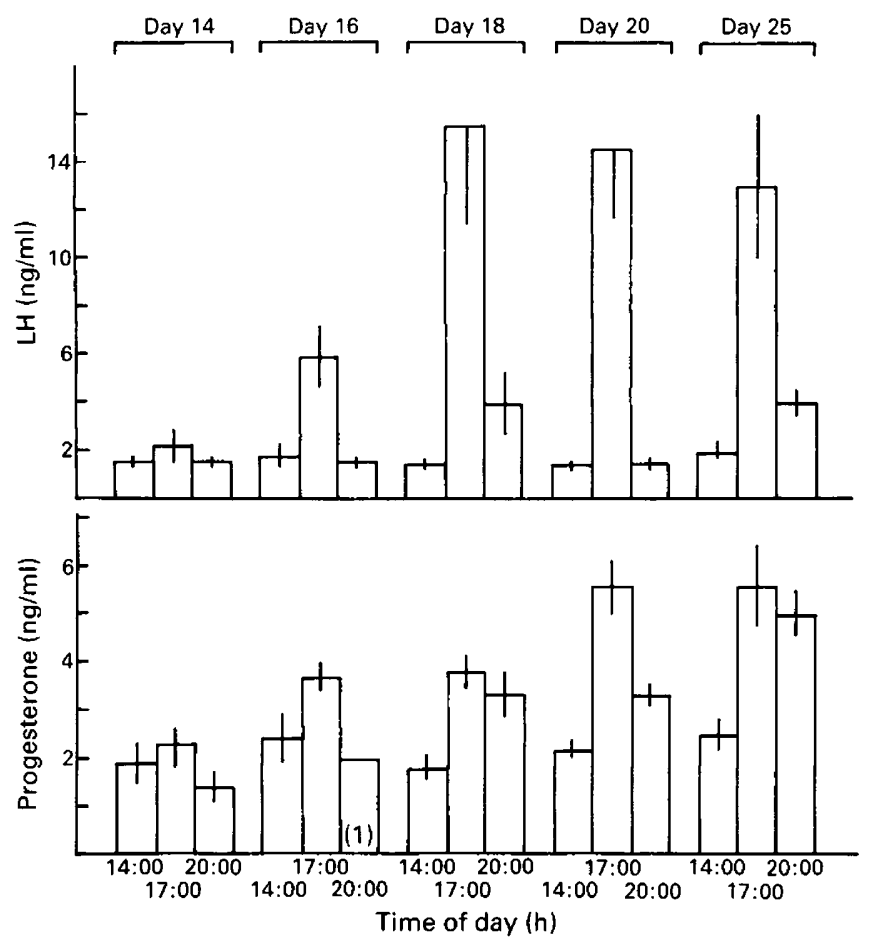

Fig. 1. Development of daily afternoon surges of LH and progesterone in immature female Syrian hamsters. Values are mean \pm s.e.m. for, except as noted, 6-8 animals per group. 
(a) Males
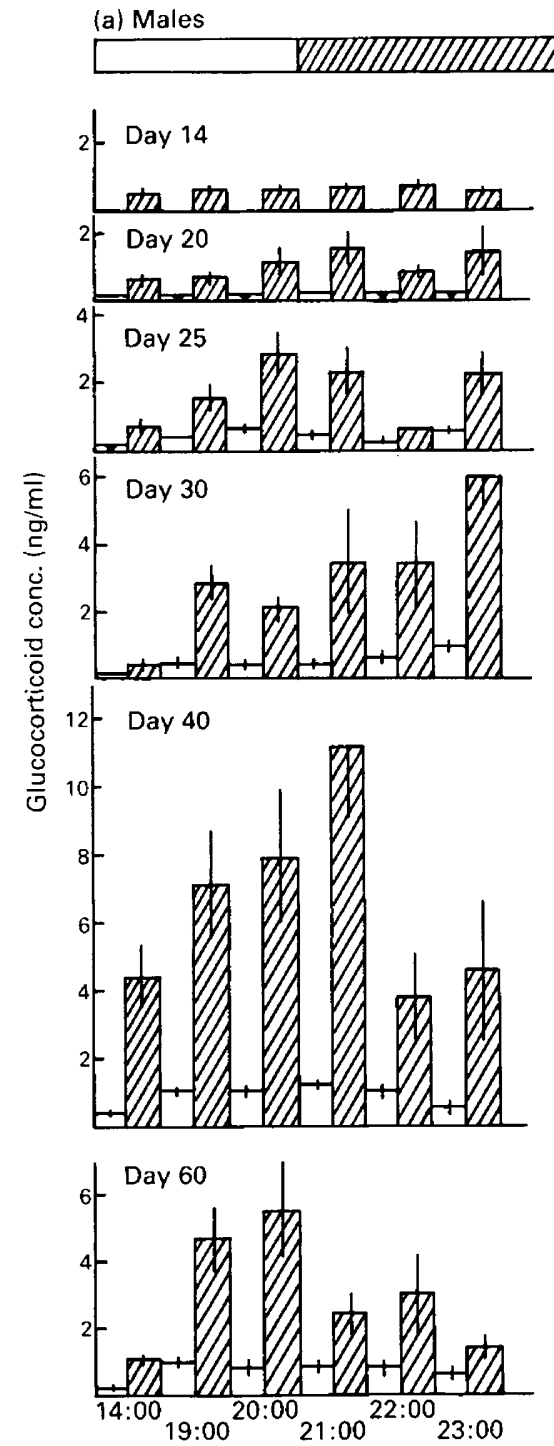

(b) Females
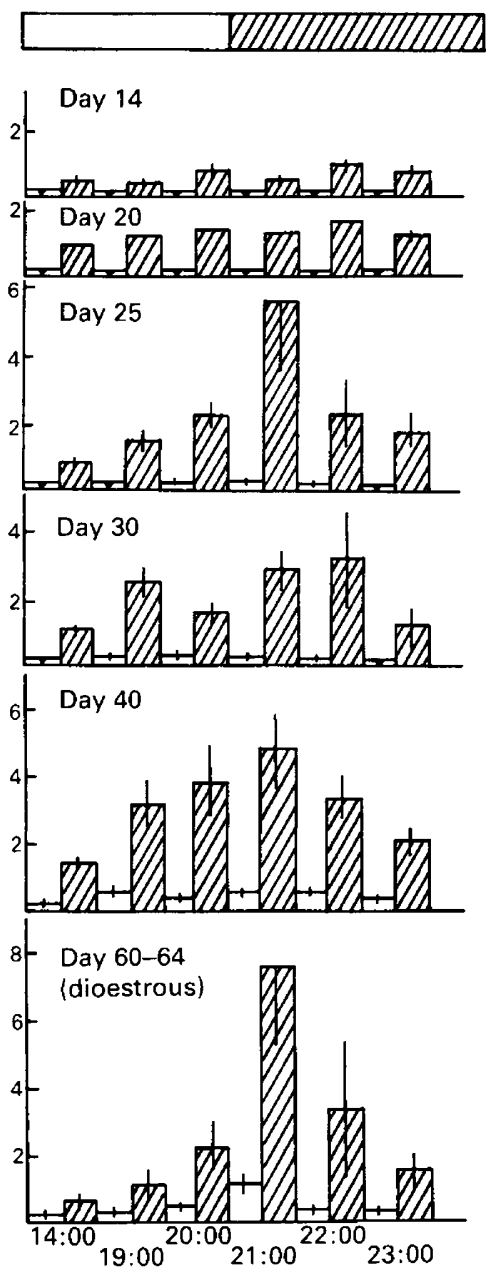

Time of day (h)

Fig. 2. Ontogeny of daily cortisol ( $(1)$ ) and corticosterone ( $\square$ ) rhythms in developing (a) male and (b) female hamsters. Values are mean \pm s.e.m. for 8 animals per group. $\nabla$, Groups in which most animals had levels below the sensitivity of the assay. A portion of the light cycle $(14 \mathrm{~L}: 10 \mathrm{D})$ is indicated by the horizontal bars at the top of the figure.

corticosteroid hormones appeared to drift, or be variable even into adult age (Figs $2 \& 3$ ). A further difference was that, whereas the daily rhythm of reproductive hormones did not occur in males (data not shown), that of the adrenocortical hormones occurred in both sexes. The concentrations of cortisol exceeded those of corticosterone in both sexes and at all ages. There was, however, a significant rhythm $(P<0.05)$ of both hormones (Fig. 2$)$ in both sexes and at all ages after Day 25 (cortisol) or Day 30 (corticosterone). A single injection of pig ACTH evoked a significant increase 

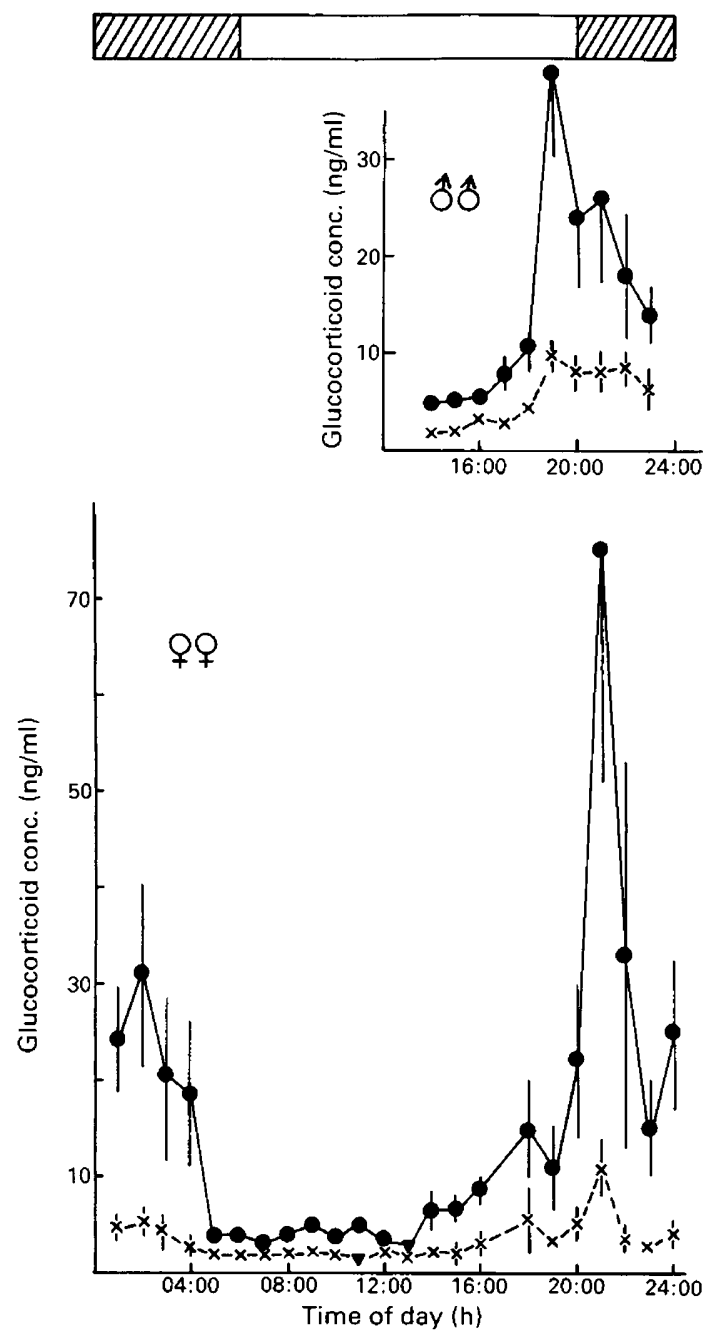

Fig. 3. Daily rhythms of serum cortisol (- - ) and corticosterone $(--\times--)$ in adult male and female Syrian hamsters. $\nabla$, Concentrations below assay sensitivity. Values are mean \pm s.e.m. for 6 females and 8 males in each group.

in cortisol levels by Day 10 of age (Fig. 4), well before the appearance of a daily rhythm. There was an unexplained lack of response to ACTH at 20 days of age. In contrast, the smaller increase in corticosterone after such an injection was not significant until Day 30, which agrees well with the appearance of the circadian rhythm of corticosterone.

Ovariectomy at 15 days of age failed to abolish the late-afternoon surge of cortisol when animals were killed at 30 days of age (Table 1). Similarly, adrenalectomy did not abolish the midafternoon surge of $\mathrm{LH}$ in immature females when adrenalectomy was performed at 21 days of age and the animals were killed at 26 days of age (Table 2).

Pinealectomy at 15 days of age did not prevent the normal late-afternoon surge of LH at 26 days of age (Table 2). In two separate experiments, ovariectomy at 21 days of age had no effect on the normal pattern of pineal melatonin, at 28 or 30 days of age (Fig. 5). 


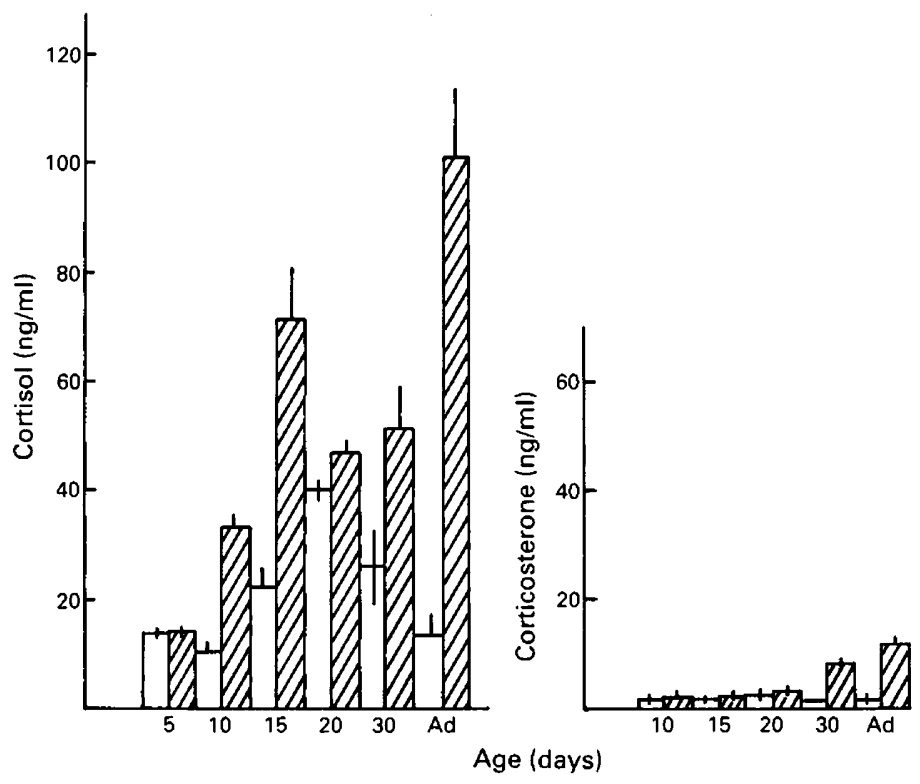

Fig. 4. Increase in cortisol and corticosterone concentrations after injection (at 13:00 h) of pig ACTH $(50 \mu \mathrm{g} / \mathrm{kg})$. Open bars are levels in samples collected at the time of injection, shaded bars represent levels after $30 \mathrm{~min}$. Values are mean \pm s.e.m. for 5-8 animals per group. Ad $=$ adult.

Table 1. Cortisol concentrations in serum $(\mathrm{ng} / \mathrm{ml})$ of 30-day-old hamsters, sham-ovariectomized or ovariectomized at 15 days of age

\begin{tabular}{ccc}
\hline $\begin{array}{c}\text { Time } \\
(\mathrm{h})\end{array}$ & Sham ovariectomy & Ovariectomy \\
\hline $13: 00$ & $4 \cdot 6 \pm 0.06(8)$ & $<4 \cdot 0(4)$ \\
$17: 00$ & $5 \cdot 7 \pm 0.17(7)$ & $6 \cdot 8 \pm 0 \cdot 18(6)$ \\
$21: 00$ & $22 \cdot 7 \pm 4 \cdot 6(5)^{*}$ & $21.9 \pm 4 \cdot 7(6)^{*}$ \\
\hline
\end{tabular}

Values are mean \pm s.e.m. for the no. of hamsters indicated in the parentheses.

${ }^{*} P<0.01$ as compared to $13: 00 \mathrm{~h}$ group.

Table 2. Serum LH concentrations in adrenalectomized or pinealectomized immature female hamsters

\begin{tabular}{lcccr}
\hline \multicolumn{1}{c}{ Treatment } & $\begin{array}{c}\text { Age at } \\
\text { surgery } \\
\text { (days) }\end{array}$ & $\begin{array}{c}\text { Age at } \\
\text { death } \\
\text { (days) }\end{array}$ & \multicolumn{2}{c}{ LH (ng/ml) } \\
\hline Sham-adrenalectomy & 21 & 27 & $0 \cdot 9 \pm 0.4 \mathrm{~h}$ & $17: 00 \mathrm{~h}$ \\
Adrenalectomy & 21 & 27 & $1 \cdot 4 \pm 0 \cdot 4(4)$ & $7 \cdot 6 \pm 0 \cdot 8(6)^{*}$ \\
Sham-pinealectomy & 15 & 30 & $3 \cdot 3 \pm 0 \cdot 3(5)$ & $8 \cdot 1 \pm 1 \cdot 1(5)^{*}$ \\
Pinealectomy & 15 & 30 & $2 \cdot 6 \pm 0 \cdot 3(5)$ & $9 \cdot 2 \pm 1 \cdot 4(6)^{*}$ \\
\hline
\end{tabular}

Values are mean \pm s.e.m. of the no. of hamsters indicated in parentheses.

${ }^{*} P<0.01$ as compared to the 13:00 $\mathrm{h}$ group. 


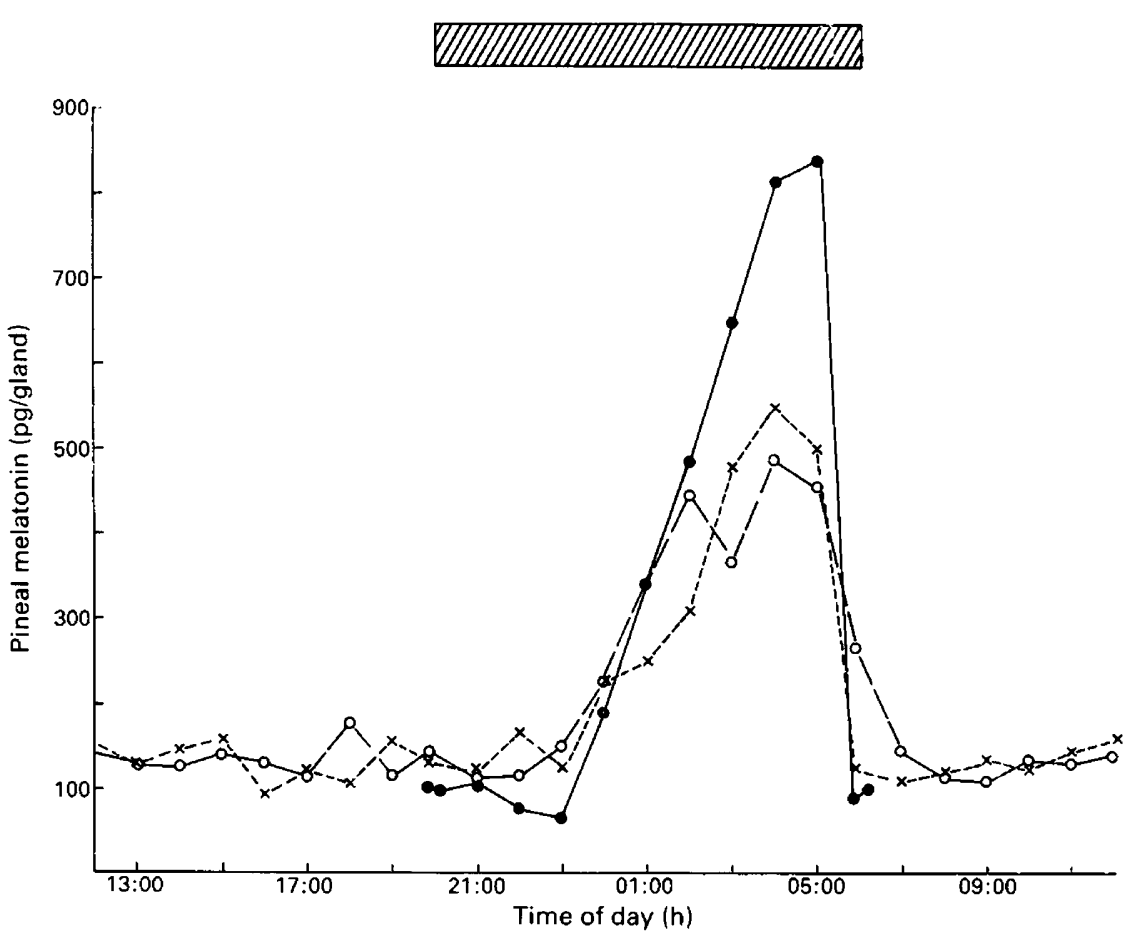

Fig. 5. Pineal melatonin content in ovariectomized and intact hamsters. Immature hamsters (-- -- , 28-day old; -- $x--, 30$-day old) were ovariectomized at 21 days of age. Intact controls (- - ) were pregnant adult females. Dark period indicated by the shaded bar. $\mathrm{N}=6-8$ in each group.

\section{Discussion}

The results reported here suggest that daily rhythms of function in the brain-pituitary-ovarian axis, the brain-pituitary-adrenal axis and the pineal gland develop independently. Twenty-four hour rhythms of cortisol and corticosterone were not detectable in the circulation until at least 25 days of age and thus trailed the appearance of a daily rhythm of circulating progesterone by about 1 week and that of LH and pineal melatonin by at least 8 days. Until at least 40 days of age, the daily afternoon surges of cortisol and corticosterone were variable in both phase and magnitude (Fig. 2). In contrast, the rhythms of serum LH and progesterone appeared abruptly and were both robust and consistent (Fig. 1, also see Donham et al., 1984, 1986, 1987).

The independence of the pituitary-ovarian and pituitary-adrenal axes is further illustrated by the lack of effect of adrenalectomy on the daily surge of $\mathrm{LH}$ and of ovariectomy on the afternoon surge of cortisol (Tables 1 and 2). Furthermore, pinealectomy did not prevent the normal appearance of the late afternoon surge of LH (Table 2). Conversely, ovariectomy of immature hamsters did not significantly alter the nocturnal peak of pineal melatonin (Fig. 5). In this study, the pineal melatonin rhythm in intact animals represents tissue collected from pregnant adults (Day 5 of pregnancy). In many other experiments, pineal melatonin values of both juvenile and adult animals exhibit a pattern similar to that of the three groups examined in this study (Tamarkin $e t$ al., 1980; Rollag \& Stetson, 1981; Stetson \& Watson-Whitmyre, 1984). In summary, these results suggest that circadian rhythms of pituitary gonadotrophin release are independent of pineal function and also that rhythms of pineal melatonin content are not affected by ovarian secretions.

Whereas the daily rhythms of $\mathbf{L H}$ and progesterone are present in the female hamster only, and are abolished by the administration of androgens to the neonate (Donham \& Stetson, 1985), 24-h 
rhythms of adrenocortical function did not differ consistently between the male and female (Figs 2 \& 3). For cortisol at least, the appearance of the daily rhythm, and specifically the late afternoon surge, did not depend on the competence of the adrenal cortex to respond to stimulation by ACTH, since the administration of ACTH elicited an adult-like increase in circulating cortisol as early as 15 days of age (Fig. 4). In contrast, the rhythmic release of corticosterone may reflect adrenocortical maturation since the serum levels first increased after ACTH at 30 days of age.

It appears probable that each rhythm is an independent expression of a circadian oscillator system in the SCN and a set of neuroendocrine effectors. The appearance of these rhythms may represent, at least in part, maturation of the retinohypothalamic tract, the SCN or the necessary neuroendocrine effectors. In the hamster, completion of direct retinal projections to the SCN is delayed until the 2 nd week after birth (Frost et al., 1979) and therefore coincides well with the start of adult patterns of rhythmic pineal and pituitary activity. Despite clearly demonstrated fetal metabolic rhythms (Reppert \& Schwartz, 1983), rhythmic neuronal output from the rat SCN may not occur until about 14 days of age (Shibata et al., 1983). These reports and evidence that there is post-natal transformation of the gonadotrophin-releasing hormone cell subtypes (Wray \& Hoffman, 1986) and that synaptic formation in the hypothalamus occurs at least until about the age of puberty (Matsumoto \& Arai, 1976) suggests that neuronal maturation occurs after birth.

The adrenal cortex of the Syrian hamster secretes both cortisol and corticosterone in a rhythmic fashion. Albers et al. (1985) also report 24-h rhythms of both cortisol and corticosterone and suggest that dominance of a particular steroid depends on time of day. We find that at all times and in both sexes cortisol is the major steroid. Since the amplitude of the cortisol rhythm is greater than that of corticosterone and since the increase of cortisol after stress is greater than that of corticosterone (Guerrier et al., 1975; Ottenweller et al., 1985) there seems little advantage to the measurement of corticosterone in physiological studies of the hamster.

The Syrian hamster is apparently unique among species so far studied in the development of circadian rhythms of gonadotrophin release well before the pubertal stage. In the rat a circadian pattern of LH has been described between the ages of 13 and 18 days (Döhler \& Wuttke, 1976) but this is apparently a transient expression. Later (30-38 days), a prolonged 'minisurge' develops which enhances ovarian secretion of progesterone and oestradiol in the peripubertal ovary (Urbanski \& Ojeda, 1985a, b). In this regard, the daily afternoon surges are as effective in stimulating the endocrine development of the ovaries as are constant high levels of LH and hence are a functionally more efficient means of achieving the increasing concentrations characteristic of the peripubertal phase. The daily surges in the female hamster, which develop by 16 days of age and persist until puberty, almost certainly serve the same function (Donham et al., 1984, 1986, 1987) and, in addition, stimulate development of the gametogenic ovary.

The temporal pattern of ovarian maturation in the hamster differs from that of the rat. In the latter, antral follicles develop several weeks before the first ovulations (Rennels, 1951) and ovulation can be induced prematurely. In the hamster, however, at the time of appearance of the daily gonadotrophin surges, the most advanced ovarian follicles consist of 2 or 3 layers of granulosa cells (Greenwald \& Peppler, 1968). Between 14 and 21 days of age a marked hypertrophy of the interstitium occurs (and progesterone secretion is augmented). By Day 26 large secondary follicles are present, the first antral follicles are observed and the first spontaneous ovulations occur. It is at this time that ovulation can first be induced by administration of exogenous gonadotrophins (Greenwald \& Peppler, 1968). Prepubertal ovarian development in the hamster thus appears to be dependent on and regulated by the daily stimulation of circulating $\mathrm{LH}$ and FSH surges.

We thank Ms Sandra Lynn Ray and Mr Romeo Morales for valuable technical assistance. This work was supported by an NIH Research Grant HD18481 (R.S.D.), an NSF Research Grant DCB84-12487 (M.H.S.), a Biomedical Research Grant from the University of Delaware (R.S.D.) and U.S.H.U.S. Protocols RO7039 and CO7049 (M.D.R.). 


\section{References}

Abraham, G.E., Manlimos, F.S. \& Garza, R. (1977) Radioimmunoassay of steroids. In Handbook of Radioimmunoassay, pp. 591-656. Ed. G. E. Abraham. Marcel Dekker, New York.

Albers, H.E., Yogev, L., Todd, R.B. \& Goldman, B.D. (1985) Adrenal corticoids in hamsters: role in circadian timing. Am. J. Physiol. 248, R434-R438.

Allen, C. \& Kendall, J.W. (1967) Maturation of the circadian rhythm of plasma corticosterone in the rat. Endocrinology 80, 926-930.

Döhler, K.D. \& Wuttke, W. (1976) Circadian fluctuations of serum hormone levels in prepubertal male and female rats. Acta endocr., Copenh. 83, 269-279.

Donham, R.S. \& Stetson, M.H. (1985) Neonatal androgen abolishes clock-timed gonadotrophin release in prepubertal and adult female hamsters. J. Reprod. Fert. 73, 215-221.

Donham, R.S., DiPinto, M.N. \& Stetson, M.H. (1984) Twenty-four hour rhythms of gonadotropin release induces cyclic progesterone secretion by the ovary of prepubertal and adult hamsters. Endocrinology 114, $82 \mathrm{l}-826$.

Donham, R.S., DiPinto, M.N. \& Stetson, M.H. (1985) Effects of ovariectomy on clock-timed gonadotropin rhythms in prepubertal golden hamsters. Biol. Reprod. 32, $284-289$.

Donham, R.S., Creyaufmiller, N., Lyons, T.J. \& Stetson, M.H. (1986) Temporal relationship between the onset of daily gonadotrophin surges and of puberty in female golden hamsters. J. Endocr. 108, 219-224.

Donham, R.S., von Posern, F. \& Stetson, M.H. (1987) Daily rhythms of serum luteinizing hormone in the immature hamster are estradiol-dependent. Biol. Reprod. 36, 864-870.

Foster, D.L., Yellon, S.M. \& Olster, D.H. (1985) Internal and external determinants of the timing of puberty in the female. J. Reprod. Fert. 75, 327-344.

Frost, D.O., So, K.-F. \& Schneider, G.E. (1979) Postnatal development of retinal projections in Syrian hamsters: a study using autoradiographic and anterograde degeneration techniques. Neuroscience 4, 1649-1677.

Goldman, B.D. \& Darrow, J.M. (1983) The pineal gland and mammalian photoperiodism. Neuroendocrinology 37, 386-396.

Goldman, B.D., Darrow, J.M. \& Yogev, L. (1984) Effects of timed melatonin infusions on reproductive development in the Djungarian hamster (Phodopus sungorus). Endocrinology 114, 2074-2083.

Greenwald, G.S. \& Peppler, R.D. (1968) Prepubertal and pubertal changes in the hamster ovary. Anat. Rec. 161, 447-458.

Guerrier, D., Thonnerieux, M. \& Pellet, H. (1975) Dosage du cortisol et de la corticostérone dans le plasma et les surrénales de Hamster doré (Mesocricetus auratus). C. r. hebd. Séanc. Acad. Sci., Paris D 280, 2781-2784.

Matsumoto, A. \& Arai, Y. (1976) Developmental changes in synaptic formation in the hypothalamic arcuate nucleus of female rats. Cell Tiss. Res. 169, 143-156.

Moore, R.Y. \& Eichler, V.B. (1972) Loss of circadian adrenal corticosterone rhythm following suprachiasmatic lesions in the rat. Brain Res. 42, 201-206.

Moore-Ede, M.C. (1986) Physiology of the circadian timing system: predictive versus reactive homeostasis. Am. J. Physiol. 250, R735-R752.

Ottenweller, J.E., Tapp, W.N., Burke, J.M. \& Natelson, B.H. (1985) Plasma cortisol and corticosterone concentrations in the golden hamster (Mesocricetus auratus). Life Sci. 37, 1551-1558.

Rennels, E.G. (1951) Influence of hormones on the histochemistry of ovarian interstitial tissue in the immature rat. Am. J. Anat. 88, 63-108.

Reppert, S.M. \& Schwartz, W.J. (1983) Maternal coordination of the fetal biological clock in utero. Science, N.Y. 220, 969-971.

Rollag, M.D. \& Stetson, M.H. (1981) Ontogeny of the pineal melatonin rhythm in golden hamsters. Biol. Reprod. 24, 311-314.

Rusak, B. \& Zucker, I. (1979) Neural regulation of circadian rhythms. Physiol. Rev. 59, 449-526.

Shibata, S., Lious, S.Y. \& Ueki, S. (1983) Development of the circadian rhythm of neuronal activity in suprachiasmatic nucleus of rat hypothalamic slices. Neurosci. Lett. 43, 231-234.

Sizonenko, P.C., Lang, V., Rivest, R.W. \& Aubert, M.L. (1985) The pineal and pubertal development. In Photoperiodism, Melatonin and the Pineal (Ciba Fdn Symp. No. 117), pp. 208-225. Pitman, London.

Smith, S.G. \& Stetson, M.H. (1980) Maturation of the clock-timed gonadotropin release mechanism in hamsters: a key event in the pubertal process? Endocrinology 107, 1334-1337.

Stetson, M.H. \& Anderson, P.J. (1980) Circadian pacemaker times gonadotropin release in free-running female hamsters. Am. J. Physiol. 238, R23-R27.

Stetson, M.H. \& Watson-Whitmyre, M. (1976) Nucleus suprachiasmaticus: the biological clock in the hamster? Science, N.Y. 191, 197-199.

Stetson, M.H. \& Watson-Whitmyre, M. (1984) Physiology of the pineal and its hormone melatonin in annual reproduction in rodents. In The Pineal Gland, pp. 109-153. Ed. R. J. Reiter. Raven Press, New York.

Stetson, M.H., Sarafidis, E. \& Rollag, M.D. (1986) Sensitivity of adult male Djungarian hamsters (Phodopus sungorus sungorus) to melatonin injections throughout the day: effects on the reproductive system and the pineal. Biol. Reprod. 35, 618-623.

Takahashi, K., Hanada, K., Kobayashi, K., Hayafuji, C., Otani, S. \& Takahashi, Y. (1979) Development of the circadian adrenocortical rhythm in rats: studied by determination of 24- or 48-hour patterns of blood corticosterone levels in individual pups. Endocrinology 104, 954-961.

Tamarkin, L., Reppert, S.M., Orloff, D.J., Klein, D.C., Yellon, S.M. \& Goldman, B.O. (1980) Ontogeny of the pineal melatonin rhythm in the Syrian (Mesocricetus auratus) and Siberian (Phodopus sungorus) hamsters and in the rat. Endocrinology 107, 1061-1064.

Urbanski, H.F. \& Ojeda, S.R. (1985a) In vitro simulation 
of prepubertal changes in pulsatile luteinizing hormone release enhances progesterone and $17 \beta$ estradiol secretion from immature rat ovaries. Endocrinology 117, 638-643.

Urbanski, H.F. \& Ojeda, S.R. (1985b) The juvenileperipubertal transition period in the female rat: establishment of a diurnal pattern of pulsatile luteinizing hormone secretion. Endocrinology 177, 644-649.
Weinberg, J. \& Wong, R. (1986) Adrenocortical responsiveness to novelty in the hamster. Physiol. Behav. 37, 669-672.

Wray, S. \& Hoffman, G. (1986) Postnatal morphological changes in rat LHRH neurons correlated with sexual maturation. Neuroendocrinology 43, 93-97.

Received 20 November 1987 